\title{
Analysis of shallow-groundwater dynamic responses to water supply change in the Haihe River plain
}

\author{
ZHOU LIN, WANG LIN \& LIN PENGFEI
}

State Key Laboratory of Simulation and Regulation of Water Cycle in River Basins, China Institute of Water Resources and Hydropower Research, Beijing, China

wanglin@iwhr.com

\begin{abstract}
When the middle route of the South-to-North Water Diversion Project is completed, the water supply pattern of the Haihe River plain in North China will change significantly due to the replenishment of water sources and groundwater-exploitation control. The water-cycle-simulation model - MODCYCLE, has been used in simulating the groundwater dynamic balance for 2001-2010. Then different schemes of water supply in 2020 and 2030 were set up to quantitatively simulate the shallow-groundwater dynamic responses in the future. The results show that the total shallow-groundwater recharge is mainly raised by the increases in precipitation infiltration and surface-water irrigation infiltration. Meanwhile, the decrease of groundwater withdrawal contributes to reduce the total discharge. The recharge-discharge structure of local groundwater was still in a negative balance but improved gradually. The shallow-groundwater level in most parts was still falling before 2030, but more slowly. This study can benefit the rational exploitation of water resources in the Haihe River plain.
\end{abstract}

Key words Haihe River plain; MODCYCLE model; shallow groundwater; dynamic responses; water supply pattern

\section{INTRODUCTION}

As one of China's most important economic development regions as well as a water stress area, the Haihe River plain depends strongly on groundwater supply. The proportion of groundwater in the total water supply grows steadily and has reached $66 \%$ recently. This region has been the most serious groundwater-overdraft area among all the regions benefitting from the South-to-North Water Diversion Project (SNWDP) due to the effect of both the rapid growth in water requirements and the gradual reduction of precipitation since the 1980s. Long-term over-pumping for groundwater leads to excessive consumption of the groundwater storage in the Haihe River plain. The groundwater level drops and the groundwater cone of depression expands year by year, leading to ground subsidence, seawater flowing backward, water pollution and other kinds of severe environmental and geological problems. In order to ensure the sustainable utilization of groundwater in the Haihe River plain and the steady and healthy development of the regional economy and society as well as the ecology and environment, the issues of groundwater resources assessment and research have been one of the topics in academic research for many years.

Han (2002) built a shallow groundwater model of the Haihe River plain and put forward some suggestions for future model construction, through analysis of the process of depletion of groundwater storage in the Haihe River plain. Fei et al. (2001) indicates the exploitation potential of groundwater is very limited in this area and the SNWDP is an ideal way to resolve the problem of water shortage in the long run. Based on the theory of water balance, He (2003) points out that after the implementation of SNWDP, the decrease of groundwater exploitation and increase of groundwater recharge will lead to the partial recovery of shallow groundwater in Haihe River plain. Du et al. (2011) combined the MODFLOW model with the water allocation model ROWAS and simulated the evolution of groundwater in the Haihe River plain under two scenarios: with and without the SNWDP.

These studies have evaluated the groundwater resource in the Haihe River plain through data analysis and model simulation methods. But the hydrologic series for the simulation of hydrological conditions is short and the number of schemes considered is small. To verify the effect of the project in recovering the groundwater circulation from a multi-angle perspective, this paper combined several typical patterns of water supply with the distributed hydrological MODCYCLE model to simulate and predict the shallow groundwaters dynamic response under different series of hydrological conditions (1956-2000 series and 1980-2005 series) and 
implementation of the SNWDP (when the middle-route first phase works, second phase works and middle-route first phase gets $20 \%$ water diversion added).

\section{CONSTRUCTION AND VALIDATION OF MODCYCLE FOR HAIHE RIVER PLAIN}

\subsection{Data input of model}

MODCYCLE is a distributed water-cycle-simulation model based on the "nature-society" characteristics of water circulation, which can be used for the simulation and quantification of the water-cycle system that is severely impacted by human activities in the Haihe River plain. The structure of the model is as follows: according to the DEM, the study region is divided into several sub-basins. Then they are further divided into multi basic simulated units which are relatively independent; land use, management and soil type data are also treated in the same way. Natural water pools, swamps and lakes are also be included in the sub-basins. Besides, the groundwater system has both shallow and deep parts and the channels have two levels which are called main and sub-channels. The runoff from these basic simulated cells flows into the sub-channels, pools, swamps, lakes or main channels, thus forming a stream network system in which the reservoirs are allowed. At last, the hydraulic relations among sub-basins are established by the network system.

Based on above description, the Haihe River basin was divided into 2028 sub-basins, and the number of sub-basins of the plain is 1165 . The numerical simulation of groundwater was based on the distance of 4-km grid cells in which the number of effective cells is 8383 . The number of basic simulated cells is 40259 . The groundwater level is calculated from the interpolation of the data collected from observation wells. The meteorological data, hydrogeological parameters and other engineering information are also considered. Then land surface and river hydrological processes considering human activities are simulated by MODCYCLE with these data.

\subsection{Validation of model}

The years from 2001 to 2005 were taken as the calibration period, and 2006-2010 as the validation period. Considering the circulation characteristics of the water cycle in the Haihe River basin, the groundwater level and the variable storage of groundwater were selected as the validation indicators. Figure 1 shows the comparison at the end of 2010 (end of validation period) between the modelling and surveying results as shallow groundwater contours. Overall, the two results are comparable. Figure 2 compares the statistical results (based on the analysis and arrangement of the data from the Haihe Water Resources Bulletin) and simulated values of the variation of shallow groundwater storage in 2001-2010. The results show they have the same trend. The correlation between the statistical and simulated values is 0.96 . In general, the current calibration-validation results meet the requirements for this type of water-cycle simulation research in the long term and large spatial scale of the Haihe River basin.

\section{PRESENT SITUATION OF GROUNDWATER BALANCE AND THE SETTING OF SIMULATED SCENARIOS}

\subsection{The status quo of shallow groundwater dynamic balance in 2001-2010}

The total shallow groundwater recharge of the Haihe River plain is about 19.4 billion $\mathrm{m}^{3}$ on average in the simulated current status. As the major source of supply, the precipitation infiltration accounts for $67.0 \%$ of the total recharge; the irrigation infiltration accounts for $8.7 \%$. The total annual average of shallow groundwater discharge is 22.4 billion $\mathrm{m}^{3}$ in which agricultural production accounts for $49.7 \%$ followed by the industrial, urban life, ecological and other nonagricultural production, accounting for $27.4 \%$ of the total discharge.

\subsection{The main characteristics of water-supply-pattern schemes}

The recommended scheme F1 is based on normal series of 1956-2000 (long series) from the Haihe River basin water resources comprehensive planning. By the consideration of coordination in $5 \mathrm{~d}$ 

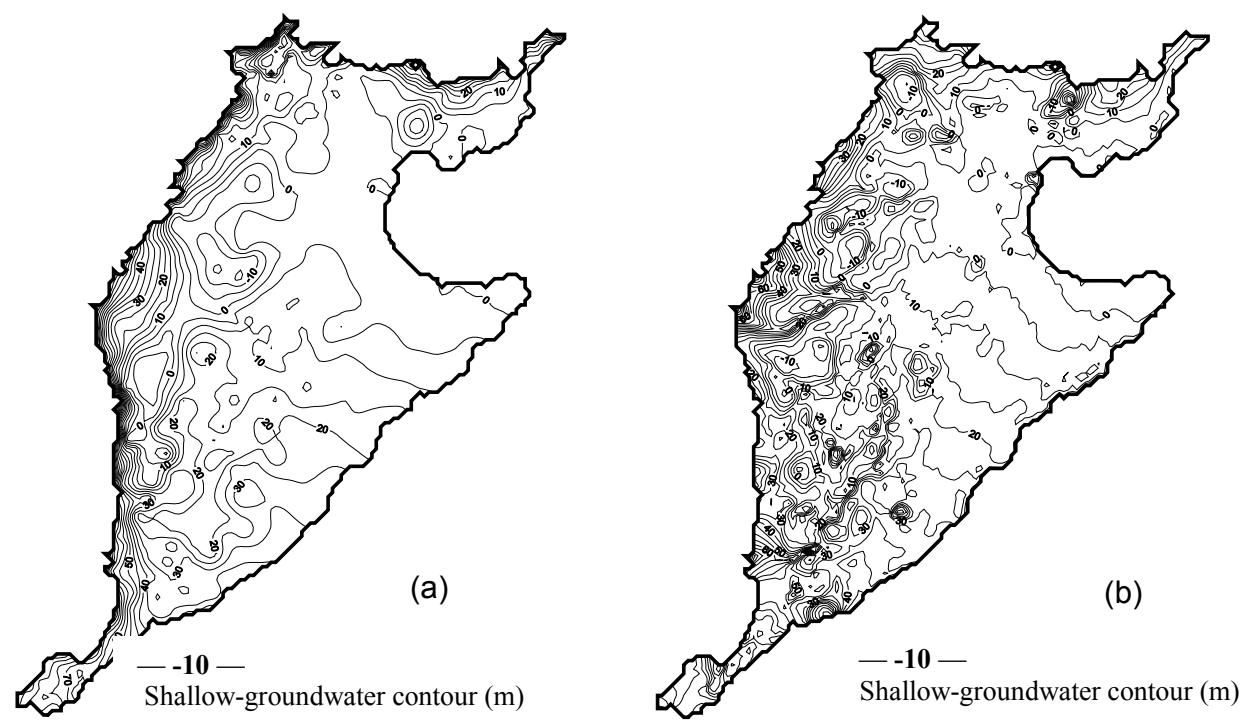

Fig. 1 The shallow groundwater surveyed (a) and modelling (b) flow fields at the end of validation.

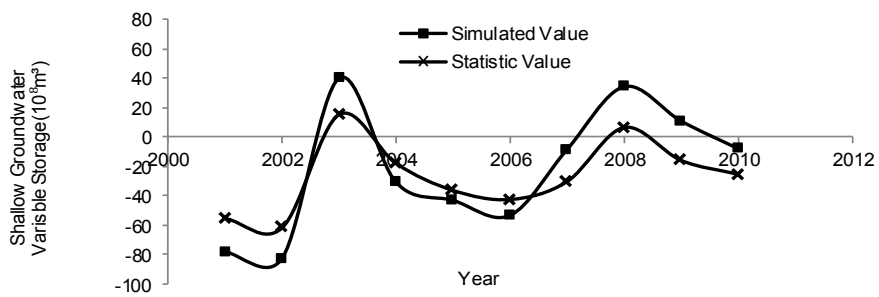

Fig. 2 The shallow groundwater storage curve of the Haihe River basin from 2001 to 2010.

attributes, F1 was chosen for the basic solution. But this hydrologic series of the river basin reflected the recent local water-resources situation insufficiently. So with the recent low water series of 1980-2005 (short series) as a comparison, finally five typical schemes under changing water supply pattern were determined, including long-series schemes (F1, F2 and F3) and shortseries schemes (F4 and F5). The main characteristics are shown in Table 1.

Table 1 The main constrained characteristics of the five different schemes $\left(10^{8} \mathrm{~m}^{3}\right)$.

\begin{tabular}{|c|c|c|c|c|c|c|c|c|}
\hline \multicolumn{2}{|c|}{ Scheme } & \multirow{3}{*}{$\begin{array}{l}D \\
7.9\end{array}$} & \multirow{3}{*}{$\begin{array}{l}G \\
3.6\end{array}$} & \multirow{3}{*}{$\begin{array}{l}S \\
3.6\end{array}$} & \multirow{3}{*}{$\begin{array}{l}U \\
2.9\end{array}$} & \multicolumn{3}{|c|}{ Completion of SNWDP } \\
\hline & & & & & & \multirow{2}{*}{$\begin{array}{l}\begin{array}{l}\text { First } \\
\text { phase }\end{array} \\
\sqrt{ }\end{array}$} & \multirow[t]{2}{*}{$\begin{array}{l}\text { Second } \\
\text { phase }\end{array}$} & \multirow[t]{2}{*}{$\begin{array}{l}20 \% \text { increase of } \\
\text { transfer in first phase }\end{array}$} \\
\hline F1 & 2020 & & & & & & & \\
\hline & 2030 & 11.8 & 0.0 & 0.0 & 4.7 & & $\sqrt{ }$ & \\
\hline \multirow[t]{2}{*}{$\mathrm{F} 2$} & 2020 & 7.9 & 1.6 & 3.6 & 4.2 & $\sqrt{ }$ & & \\
\hline & 2030 & 11.8 & 0.0 & 0.0 & 4.7 & & $\sqrt{ }$ & \\
\hline \multirow[t]{2}{*}{ F3 } & 2020 & 7.9 & 1.6 & 3.6 & 2.9 & $\sqrt{ }$ & & \\
\hline & 2030 & 10.6 & 0.0 & 0.0 & 3.0 & & & $\sqrt{ }$ \\
\hline \multirow[t]{2}{*}{$\mathrm{F} 4$} & 2020 & 7.9 & 5.5 & 5.5 & 5.1 & $\sqrt{ }$ & & \\
\hline & 2030 & 11.8 & 3.6 & 5.0 & 6.7 & & $\sqrt{ }$ & \\
\hline \multirow[t]{2}{*}{ F5 } & 2020 & 7.9 & 3.6 & 6.4 & 5.1 & $\sqrt{ }$ & & \\
\hline & 2030 & 10.6 & 3.6 & 5.5 & 6.7 & & & $\sqrt{ }$ \\
\hline
\end{tabular}

$D$, diverted water; $G$, groundwater overdraft; $S$, sea outflow; $U$, unconventional water use. 


\subsection{Simulated scenarios of water-supply-pattern schemes}

After the middle route of SNWDP is completed, the Haihe River basin will receive 7.92 billion $\mathrm{m}^{3}$ from the Yangtze River water in 2020, and 11.75 billion $\mathrm{m}^{3}$ in 2030 . When the project is operational, the composition of the main water supply in different level years from the five schemes are shown in Fig. 3. Local groundwater still contributes most of water supply of the Haihe River plain, then the diverted water and the local surface water; in the future, water diversion (including diverted water from the Yellow River) will continue to increase and support the water supply, and the groundwater use will decrease accordingly.

The distribution of shallow groundwater and diversion (including the diverted water from the Yellow River) are shown in Fig. 4: agricultural irrigation is still the largest user of groundwater; diverted water mainly satisfies the industrial production and urban life, but after meeting the demand of economic production, it also can replace part of the groundwater overdraft which is used for agricultural irrigation and ecological-environment restoration, so alleviating the pressure of the present groundwater exploitation.

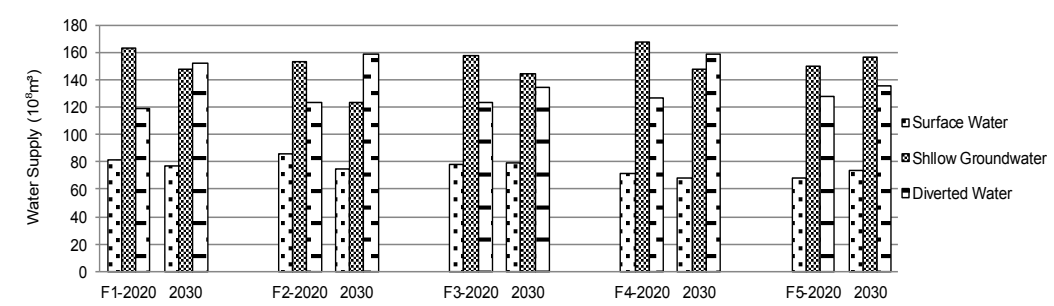

Fig. 3 The composition of main water supply from each scheme in 2020 and 2030.
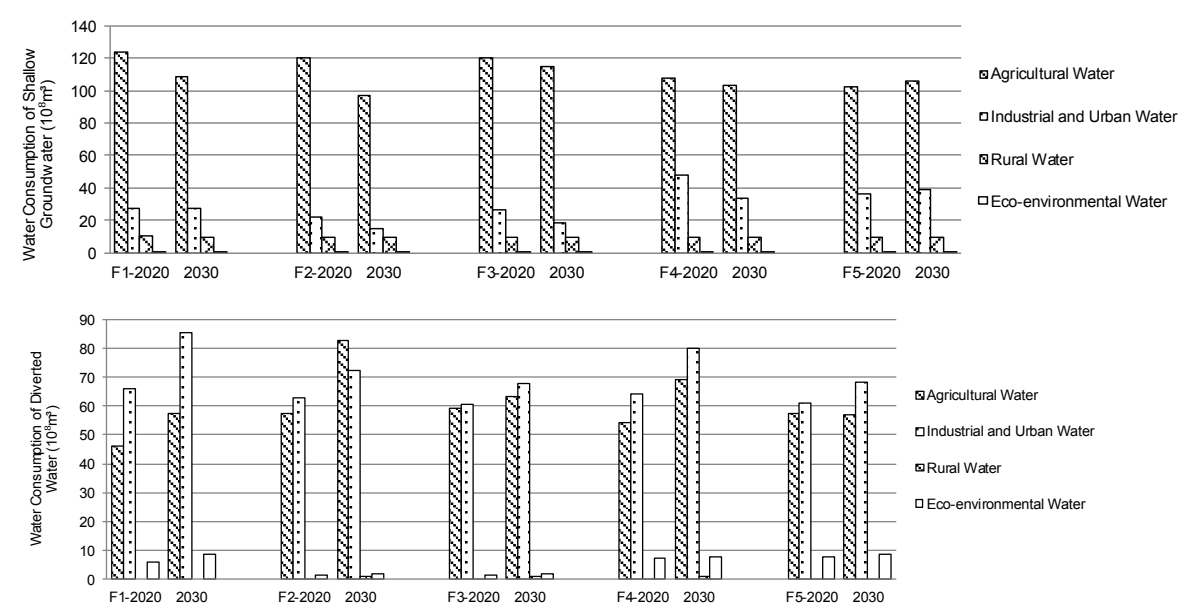

Fig. 4 The distribution from shallow groundwater and diverted water to different water-using sectors.

\section{RESULTS AND DISCUSSION}

Through the model built above, the annual average of shallow groundwater recharge, discharge and variable storage of different level years for the five water-supply-pattern schemes are predicted. The relationship among them is shown in Table 2.

Precipitation infiltration is still the main supply source of shallow groundwater, similar to the present situation; because the diverted water is mainly led through lined channels and pipes to the water users, a difference between the channel leakage of the long and short series is not obvious, and close to the average of the status quo; the increase of surface-water irrigation as well as the decrease of groundwater-irrigation exploitation collectively make irrigation infiltration of the two series greater than the present average; the total recharge of short series is about 19 billion $\mathrm{m}^{3}$, close to the present average. But mainly because of the increased amount of precipitation 
Table 2 The dynamic balance analysis of shallow groundwater in different level years and schemes $\left(10^{8} \mathrm{~m}^{3}\right)$.

\begin{tabular}{llllllllllllll}
\hline Scheme & & $P r$ & $C$ & $I$ & $S$ & $T R$ & $A$ & $O$ & $P h$ & $B$ & $L$ & $T D$ & $V$ \\
\hline \multicolumn{2}{l}{ Average of 2001-2010 } & 128 & 46 & 17 & 3 & 194 & 111 & 61 & 33 & 10 & 8 & 223 & -30 \\
F1 & 2020 & 140 & 49 & 25 & 1 & 215 & 124 & 39 & 48 & 10 & 2 & 223 & -8 \\
& 2030 & 139 & 46 & 26 & 1 & 212 & 110 & 38 & 55 & 9 & 1 & 213 & -1 \\
F2 & 2020 & 134 & 42 & 25 & 1 & 202 & 120 & 33 & 44 & 11 & 2 & 210 & -7 \\
& 2030 & 135 & 37 & 26 & 1 & 199 & 98 & 25 & 58 & 12 & 2 & 195 & 6 \\
F3 & 2020 & 133 & 43 & 25 & 1 & 202 & 120 & 37 & 40 & 11 & 2 & 210 & -9 \\
& 2030 & 135 & 41 & 25 & 1 & 202 & 115 & 29 & 50 & 10 & 1 & 205 & -5 \\
F4 & 2020 & 122 & 50 & 19 & 1 & 192 & 109 & 59 & 35 & 8 & 1 & 212 & -18 \\
& 2030 & 129 & 46 & 21 & 2 & 198 & 104 & 43 & 45 & 9 & 0 & 201 & -4 \\
F5 & 2020 & 121 & 47 & 19 & 1 & 188 & 102 & 47 & 36 & 8 & 1 & 194 & -7 \\
& 2030 & 127 & 45 & 20 & 1 & 193 & 107 & 49 & 42 & 8 & 0 & 206 & -13 \\
\hline
\end{tabular}

$\operatorname{Pr}$, precipitation infiltration; $C$, channel leakage; $I$, irrigation infiltration; $S$, shallow lateral recharge; $T R$, total recharge; $A$, agricultural production; $O$, other production; $P h$, phreatic evaporation; $B$, base flow; L, leakage flow; $T D$, total discharge; $V$, variable storage.

infiltration and leakage of the surface irrigation, the total result from the short series is less than that of the long series by about 1.2 billion $\mathrm{m}^{3}$.

Local artificial groundwater production still occupies a high proportion of the total discharge, but less than the present average in different degrees, especially other production (industrial, urban life and ecological, etc.); the phreatic water evaporation of the different schemes shows major fluctuations, but greater than the average; the leakage from shallow groundwater to deep groundwater decreases rapidly, though the calculations for the long series are slightly larger than short series; the total discharge of shallow groundwater under the two series are both less than the average 22.4 billion $\mathrm{m}^{3}$ of the status quo, by the reduction of artificial production as the key factor.

Under the condition of the long series, the shallow groundwater of the Haihe River plain presents an overall negative balance in 2020, and the groundwater depth falls more on a certain trend than in 2010; however the balance becomes positive in 2030, and the depth shows an obvious upward trend compared with 2020 (Table 2 and Fig. 5).

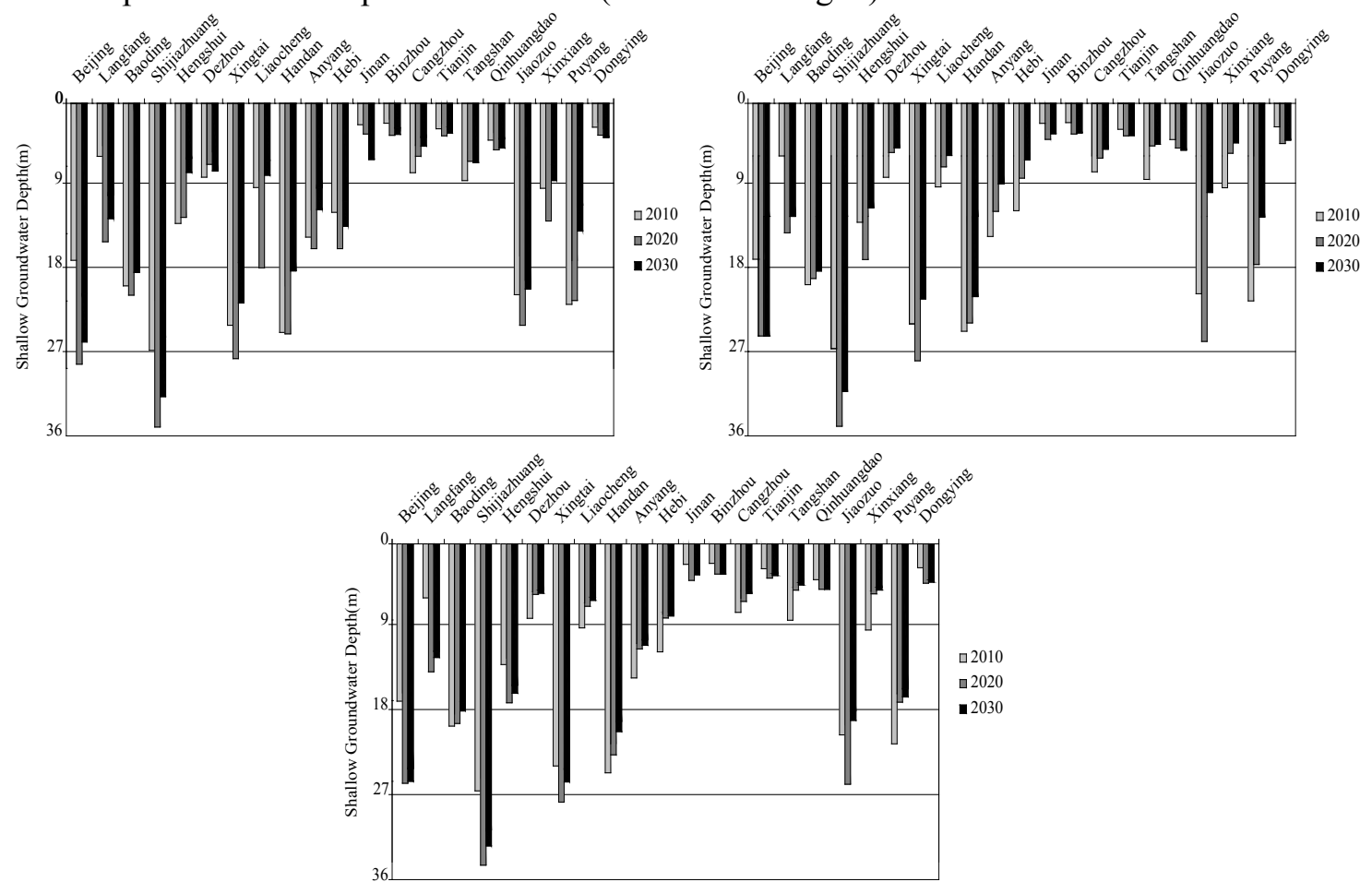

Fig. 5 The shallow groundwater depth change of schemes F1, F2 and F3 under the hydrological series from 1956 to 2000 . 
The shallow groundwater in the short series also shows a negative balance in general (Table 2). The groundwater level in 2020 and 2030 has a downward trend but at slower speed compared to 2010 (Fig. 6). Overall, though the groundwater system in the Haihe River plain is still in the negative-storage state under each scheme, the recharge-discharge structure of the local groundwater is improved a lot, relative to the minus variable storage of the present annual average which is $5-6$ billion $\mathrm{m}^{3}$ in total.
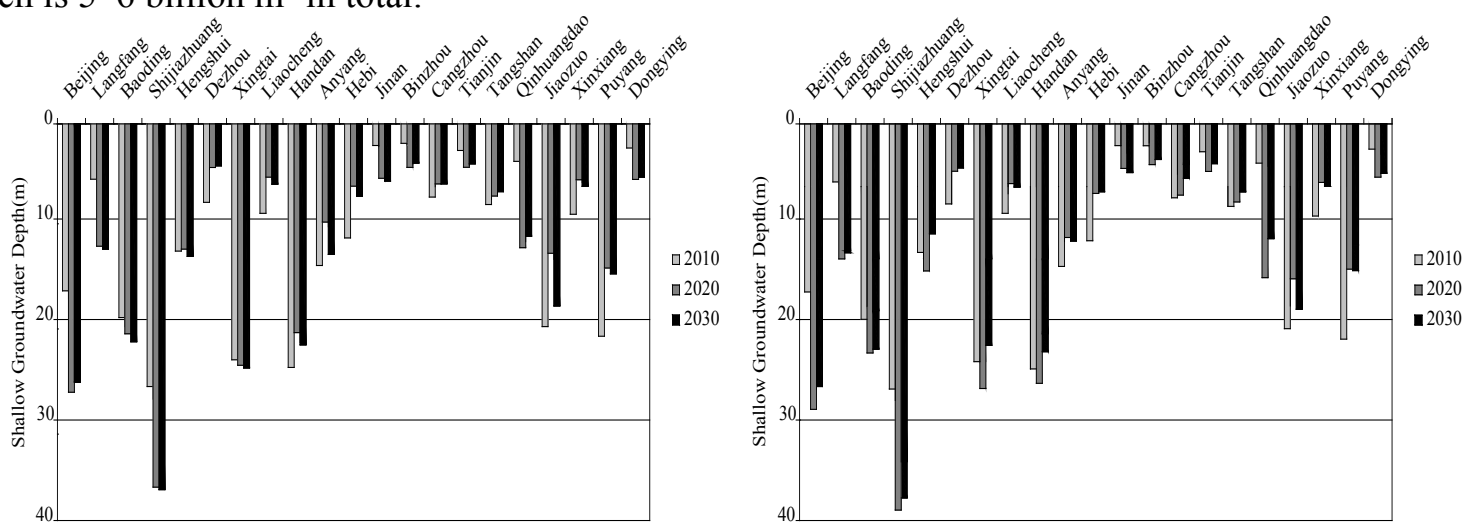

Fig. 6 Shallow-groundwater depth change of schemes F4 and F5, from 1980 to 2005.

\section{CONCLUSION}

The results of the study are as follows: (1) Recharge to shallow groundwater in the Haihe River plain would increase relative to the status quo, which is mainly caused by the increase in precipitation infiltration and surface irrigation leakage along with the change of hydrological series and water supply pattern. (2) The total discharge amount of groundwater decreases compared with the status quo due to the controlled exploitation of groundwater. (3) After the water supply pattern changes, the shallow groundwater storage state of the Haihe River plain will remain negative, but the situation would be improved a little. (4) The shallow groundwater level of the study area would overall continue to fall until 2030 , but relatively slowly.

The research shows that the SNWDP could alleviate the present situation of continuous groundwater exploitation, and improve the groundwater circulation disorder phenomenon in the study area. In the future, it is necessary to continue pushing forward the matched construction of the project in order to slow and curb the trend of environmental degradation of local groundwater. The MODCYCLE above can be considered as the daily analysis tool for Haihe River plain groundwater management. In addition, the results can provide references for promoting local sustainable groundwater development and establish further mining control mode rationally.

\section{REFERENCES}

Du, S.S. et al. (2011) Simulation study of groundwater evolution based on water resources allocation scenarios-Case study in Haihe River Basin. South-to-North Water Diversion and Water Science \& Technology 9(2), 64-68 (in Chinese).

Fei, Y.H. et al. (2001) Evolution situation and sustainable utilization prospects of groundwater resources in Haihe River Valley. Acta Geoscientia Sinica 22(4), 298-301 (in Chinese).

Fei, Y.H. et al. (2001) Shallow groundwater consumption and sustainable utilization in the plain of Haihe Valley. Hydrology 21(6), 11-13 (in Chinese).

Gan, H. et al. (2013) Multi-dimensional overall regulatory modes and threshold values for water cycle of the Haihe River Basin. Chinese Sci Bull. 58(12), 1085-1100 (in Chinese).

Han, R.G. (2002) Preliminary study of shallow groundwater model in the Plain of Haihe Valley. Haihe Water Resources 6, 15-16 (in Chinese).

He, S. (2003) Prospect analysis of shallow groundwater restoration in Haihe River Basin under the condition of South-to-North Water Diversion. Haihe Water Resources 2003(2), 20-25 (in Chinese).

Jaroslav, V. et al. (2006) Groundwater resources sustainability indicators. In: Sustainability of Groundwater Resources (ed. by. B.Webb et al.). IAHS Publ. 302, 33-52. IAHS Press, Wallingford, UK.

Jia, Y.W. et al. (2006) Development of the WEP-L distributed hydrological model and dynamic assessment of water resources in the Yellow River Basin. Journal of Hydrology 331, 606-629.

Liu, C.M. (2003) Develop ecological function of South-to-North Water Diversion Project to Repair the groundwater in North China Plain. South-to-North Water Diversion and Water Science \& Technology 1(1), 17-19. (In Chinese)

Zhang, J.E. et al. (2011) Regional runoff study based on MODCYCLE distributed hydrology model. Transactions of the Chinese Society of Agricultural Engineering 27(4), 65-71 (in Chinese). 